\title{
Tribological Properties of Polymer Composite with Impregnated Quasicrystal Nanoparticles
}

\author{
Y. A. Utkin ${ }^{1}$, A. A. Orekhov ${ }^{1}$, Thant Zin $\operatorname{Hein}^{2}$, \\ ${ }^{1}$ Moscow Aviation Institute (National Research University), \\ Moscow, Volokolamskoe shosse, 4, 125993, \\ Russia \\ ${ }^{2}$ Defense Services Technological Academy (DSTA), \\ Mandalay Lashio Highway, Pyin Oo Lwin, Mandalay Division, \\ Myanmar
}

\begin{abstract}
In this work, a study is carried out on the introduction of quasicrystal particles into a thermoplastic polymer and it is shown that this leads to changes in the structure of polyethylene. The introduction of quasicrystal particles into a thermoplastic polymer leads to changes in the structure of polyethylene: the degree of crystallinity decreases from $42 \%$ (PE) to $27 \%$ (10AlCuFe/PE) with increasing concentration of the filler, the ratio of bands corresponding to amorphous and crystalline regions in the IR spectra changes, which indicates on the amorphization of the PE structure.

The specimens have improved wear resistance (the wear rate decreased by $96 \%$ compared to the original PE), but the friction coefficient remained practically unchanged. It is shown that the addition of quasicrystal nanoparticles in a small amount (up to $10 \mathrm{wt} . \%$ ) leads to an increase in hardness, but does not have a noticeable effect on the surface roughness. The results obtained indicate that quasicrystals can serve as effective fillers for promising polymeric materials in products for aerospace, instrument making, and other industries.
\end{abstract}

Keywords-Composites, nanoparticles, tribological properties, polyethylene.

\section{INTRODUCTION}

E POXY resins are commonly used as polymer matrices in high performance composites due to their good heat resistance, durability, electrical, chemical and mechanical properties. However, its range of applications is limited due to its fragility and poor toughness. One of the ways to overcome this problem is to change the properties of epoxy matrices by introducing a rigid filler into the polymer matrix [1]-[12]. A new approach in nanotechnology proposes the use of fillers at the nanometer scale, since nanofillers have a large surface area, which makes them chemically very reactive and helps them bind better to the matrix. Nanoparticles embedded in a polymer matrix are attracting more and more interest due to the unique mechanical, optical, electrical and magnetic properties exhibited by nanocomposites and significantly improve them [13]-[16]. These improvements depend on the volumetric content of the filler as well as the type and characteristics of the nanofillers [17]-[33]. Nanofillers of a metallic or inorganic type can be considered an excellent candidate for hardening polymer matrices [34]-[43].

Modern composites have not only a wide range of physical and mechanical properties, but are also capable of directionally changing them, for example, increasing fracture toughness, regulating rigidity, strength, and other properties. These possibilities are expanded when fibers of different nature and geometry are used in composites, i.e., when creating hybrid composites. In addition, these materials are characterized by the appearance of a synergistic effect (coordinated joint action of several factors in one direction).

The main purpose of the polymer binder is to bind the filler together, to ensure the joint operation of all monofilaments (or particles, if a dispersed filler is used), to ensure the solidity of the material and the transfer (distribution) of stresses. The properties of the binder almost completely depend on: heat and heat resistance, resistance to the action of various working media (water, steam, fuel, oils, etc.), impact strength, impact strength, resistance to prolonged exposure to alternating loads, creep, stress relaxation.

After curing (for thermosetting materials) or hardening (for thermoplastic materials), the binder turns into a matrix. The 
matrix is a continuous phase, the layer thickness of which can vary from 1 to $1000 \mu \mathrm{m}$ [19].

In the "ideal" case, the binder should have the following properties: the deformation properties of the matrix should be no lower than that of the filler $\varepsilon m>\varepsilon n$; the binder should have a relatively high modulus of elasticity (E> $2000 \mathrm{MPa})$; the binder should have good adhesion to the filler ( $\tau \mathrm{sd}>20 \mathrm{MPa}$ ).

The matrix and filler must necessarily have good compatibility, however, must not dissolve in each other. Based on the factors of matrix selection: molding technology; type of production; geometric features of the resulting product; technological and operational properties in this study will be studied linear low density polyethylene.

The properties of the interface or interfacial zone, first of all, the adhesive interaction between the fiber and the matrix, determine the level of properties of composites and their retention during operation. Local stresses in the composite reach their maximum values just near or directly at the interface, where material destruction usually begins. The interface must have certain properties to ensure efficient transfer of the mechanical load from the matrix to the fiber. The adhesion bond at the interface should not be destroyed under the action of thermal and shrinkage stresses arising from the difference in the temperature coefficients of linear expansion of the matrix and fiber or as a result of chemical shrinkage of the binder during its curing.

The development of modern technology requires the creation of new structural materials with high elastic-strength characteristics, and, on their basis, structures with more effective weight data. The creation of polymer composites based on nano-modified binders has been one of the priority areas of research in the field of composite materials manufacturing technologies for many years [1]-[12]. Significant progress has been made in this area [13]-[21]. The development of composite materials that improve their operational limits is based on the reinforcement of two or more fibers into a single polymer matrix, which leads to an improved material system called hybrid composites with a wide variety of material properties [44]-[71].

When creating nanocomposites, the key tasks are the development of efficient, reliable, and affordable production technologies for mass production, which make it possible to obtain materials with stable characteristics. The hand lay technique, also called wet lay, is the simplest and most widely used process for producing flat reinforced composites. The process consists of laying layers of a polymer in successive layering using an epoxy matrix. Wet-laying is a molding process that combines layers of reinforced carbon fiber with epoxy to create a high-quality laminate. Before starting the installation process, you must prepare the appropriate form. This preparation consists of cleaning the table and applying a release agent to the surface. The manual laying process can be divided into four main steps: mold preparation, epoxy coating, laying and curing. Form preparation is one of the most important steps in the installation process. This process requires dry reinforcement layers and the application of a wet epoxy matrix. They are connected together - reinforcing material, impregnated with a matrix - epoxy resin.

The prospects for using quasicrystals are associated with coatings and films, steel hardening, and the preparation of composites with dispersed quasicrystalline fillers. The introduction of a quasicrystalline $\mathrm{Al}-\mathrm{Cu}-\mathrm{Fe}$ alloy powder into various polymers significantly increases their wear resistance at a lower abrasiveness in comparison with other fillers (plastic metals or ceramics) [1-12]. Quasicrystals (QC) are solids. As a rule, these are intermetallic phases characterized by perfect long-range order in the absence of translational symmetry and in the presence of rotational symmetry with axes of the 5th, 8 th, 10th, or 12th orders, which are forbidden in crystalline materials.

Stable QC phases are present in phase equilibrium diagrams and can be obtained by sufficiently slow cooling from the liquid. Quasicrystals of the $\mathrm{Al}-\mathrm{Pd}-\mathrm{Mn}$ system were obtained in the form of large perfect single crystals, on which, in particular, extensive studies of the regularities of their deformation were carried out.

Quasicrystals are extremely fragile. They have few dislocations, and those that are present have low mobility. As metals bend, creating and moving dislocations, the almost complete absence of movement of dislocations causes brittleness. On the positive side, the difficulty of dislocation movement makes quasicrystals extremely solid. They are highly resistant to deformation. This makes them excellent candidates for high strength surface coatings [13]-[21].

At the moment, there is a wide range of methods for the production of quasicrystalline materials, such as crystallization from melt, spontaneous crystallization methods, gas spraying, mechanical fusion, electrodeposition, physical vapor deposition, gas evaporation, laser or electron beam melting and electron irradiation, low temperature annealing of amorphous phases or high-temperature heat treatment of crystalline intermetallic phases [22]-[31]. However, the most common methods for the manufacture of $\mathrm{Al}-\mathrm{Cu}-\mathrm{Fe}$ quasicrystals are those that are accompanied by melting processes - crystallization from the melt, gas sputtering, and mechanical alloying.

The use of Al-Cu-Fe QC as a filler can significantly improve the mechanical, tribological and thermal properties of composites with a polymer matrix. Polymers filled with $\mathrm{Al}-\mathrm{Cu}-$ Fe QC show improved wear resistance and mechanical properties due to tough core with low aspect ratio. In addition, the QC powder in the polymer matrix practically does not cause abrasion of the steel counter-surface materials during wear tests [32-37]. Among the most interesting examples of $\mathrm{Al}-\mathrm{Cu}-\mathrm{Fe} \mathrm{QC}-$ filled polymers are composites based on epoxy resin, ultra-high molecular weight polyethylene (UHMWPE), polyamides, polytetrafluoroethylene, ethylene vinyl acetate, and others. 


\section{PREPARATION AND STUDY OF THE PROPERTIES OF NANOCOMPOSITES WITH QUASICRYSTALS}

Nanoparticles, even with a very low volumetric content (less than $1 \%$ ), are contained in such a fragment in a very large amount, and it is impossible to model their effect at this scale level. For example, a cubic fragment of a $1 \mu \mathrm{m}$ matrix contains more than thousand nanoparticles for a given volumetric content. Therefore, in particular, the nano-modified binder is white, while the usual binder is yellow. To model such materials, it is necessary to resort to multiscale approaches and to carry out a consistent determination of effective properties at various scale levels. This task is greatly simplified if the properties of the nanomodified matrix are known from experiments. In particular, it is known that its Young's modulus is $2.5 \mathrm{GPa}$. The missing characteristic is Poisson's ratio, which can be approximately taken unchanged, or estimated on the basis of analytical calculations using the found value of the "effective" volumetric content of the filler, which was done. Further, it suffices to numerically solve the averaging problem on a representative fragment containing only nanoparticles.

The matrix can be a thermosetting polymer - epoxy resin, which has already found many applications: from structural composites to adhesives and surface coatings. Epoxy resins already have a number of unique qualities among polymers: no shrinkage during curing, high adhesion to various substrates, good dielectric and other valuable properties [36]-[44]. Nanocomposites using thermoplastic polymers are well known and studied to improve mechanical, electrical, thermal and insulating properties.

Currently, there are a huge variety of approaches to the production of metal-polymer nanocomposites, but the most technologically advanced are processes for the production and processing of polymers, methods of introducing metal nanoparticles (ex situ and / or in situ) into a polymer melt, methods of polymerization dispersion or joint formation of a dispersed phase and a polymer matrix in one reactor.

Methods for the synthesis of nanocomposite materials (or nanocomposites) are divided into two main large approaches: in situ and ex situ. The creation of nanocomposites by the in situ method makes it possible to simultaneously (in one stage) obtain both a matrix and nanoparticles, obtaining a nanocomposite at the output. The advantage of the method is that it prevents particle agglomeration while maintaining a good spatial distribution in the polymer matrix. The main disadvantage of the method is that all the products of the synthesis of nanoparticles remain in the nanocomposite, which can deteriorate the quality and purity of the obtained material.

When using the ex situ method, each stage of nanocomposite creation is brought into a separate process: from the synthesis of nanoparticles to the preparation of a nanocomposite. This method is more energy and labor intensive compared to in situ, and requires much more time. Also, special attention should be paid to the dispersion of the nanocomponent in the matrix, since during long-term storage nanoparticles are collected into larger ones and they must be dispersed by various methods, for example, by ultrasonic treatment [1]-[8]. The ex situ synthesis method is more suitable for large scale industrial applications than the in situ method.

The ex situ method, despite all its drawbacks, is used more often than the more technologically advanced in situ method. First of all, this is due to the simplicity of the approach based on the fact that in such reactions the synthesis of nanoparticles is not complicated by additional reactions with the polymer matrix, the resulting nanocomposite will not contain byproducts associated with the formation of nanoparticles in the polymer matrix, etc.

Linear low density polyethylene (LLDPE) was used as a polymer matrix, and nanoparticles of quasicrystalline alloy $\mathrm{Al} 65 \mathrm{Cu} 22 \mathrm{Fe} 13$. The ex situ method was used for preparation of the nanocomposites - the nanoparticles were introduced into the polymer matrix by the stirring and distributed by volume. The composition, morphology and microstructure of the obtained nanocomposite materials were investigated by XRF methods (Table 1).

Table 1. XRF data for the 10A165Cu22Fe13/LLDPE nanocomposite.

\begin{tabular}{|l|l|l|l|l|}
\hline $\begin{array}{l}2 \theta / \mathrm{de} \\
\mathrm{g}\end{array}$ & $\mathrm{d} / \AA$ & $\mathrm{I}$ imp/s & Irel (\%) & Phase \\
\hline 21,70 & 4,095 & 1261 & 100 & LLDPE \\
\hline 24,10 & 3,693 & 639 & 51 & LLDPE \\
\hline 26,30 & 3,389 & 56 & 4 & LLDPE \\
\hline 36,50 & 2,462 & 67 & 5 & LLDPE \\
\hline 43,05 & 2,101 & 405 & 32 & $\begin{array}{l}\text { Al65Cu22Fe } \\
13\end{array}$ \\
\hline 45,35 & 2,000 & 379 & 30 & $\begin{array}{l}\text { Al65Cu22Fe } \\
13\end{array}$ \\
\hline 53,15 & 1,723 & 51 & 4 & LLDPE \\
\hline 55,00 & 1,670 & 63 & 5 & LLDPE \\
\hline 64,10 & 1,453 & 59 & 5 & LLDPE \\
\hline 77,05 & 1,238 & 119 & 9 & Al65Cu22Fe \\
\hline
\end{tabular}

It was found that during dispersion, filler nanoparticles are evenly fairly distributed in the volume of the matrix, and conglomerates are observed. This is confirmed by broadened peaks in X-ray diffraction patterns corresponding to the nanofiller phase (Fig. 1). Appearances other lines are not observed, which indicates the progress of the process of dispersion of the filler in the polymer matrix without phase transformations. 


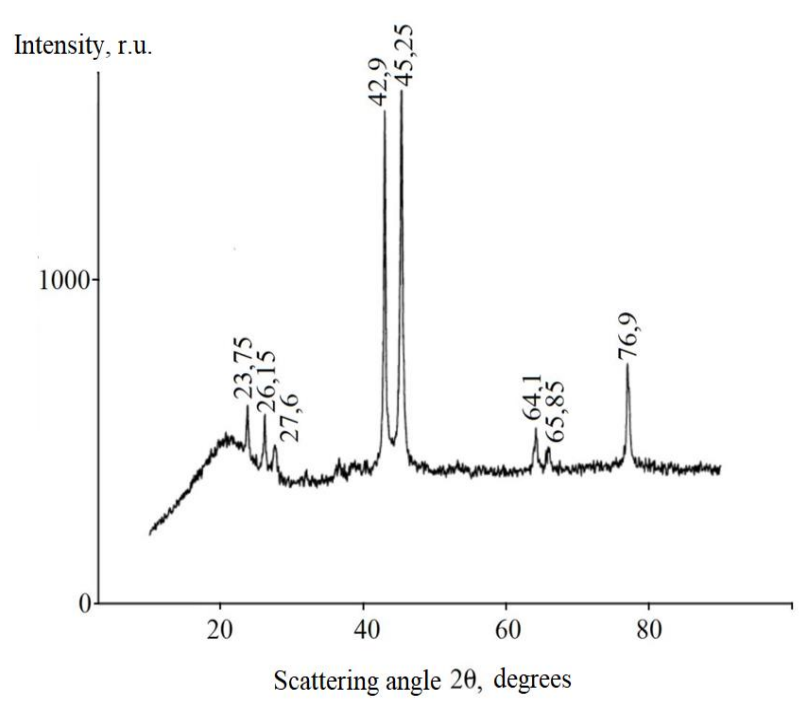

Fig. 1 x-ray diffraction pattern of Al65Cu22Fe13/LLDPE nanocomposite.

Film samples of nanocomposite materials were obtained in two modes by casting using an injection molding machine (film thickness $1,85 \mathrm{~mm}$ ) or hot pressing (film thickness 0,21 $\mathrm{mm})$.

Ensuring high wear resistance is associated with the prevention of wear, a decrease in the rates of initial and steady-state wear. Wear resistance refers to the properties of a material to resist wear under certain friction conditions estimated by the inverse of the wear rate or wear rate, therefore, the wear rate can be used to judge the durability of the part. Table 2 shows the values of the wear rate and the coefficient of friction of the obtained composites depending on the amount of filler content $\mathrm{A} 165 \mathrm{Cu} 22 \mathrm{Fe} 13$.

Table 2. The value of the coefficient of friction and the rate of wear of the composite depending on the content of the quasicrystalline alloy.

\begin{tabular}{|l|l|l|}
\hline Material & $\begin{array}{l}\text { Wear rate, } \\
\mathrm{I}, 10^{-6} \mathrm{~kg} / \mathrm{h}\end{array}$ & $\begin{array}{l}\text { Friction } \\
\text { coefficient, } \mathrm{f}\end{array}$ \\
\hline LLDPE & 40 & 0,2 \\
\hline $\begin{array}{l}\text { LLDPE }+ \\
\text { Al65Cu22Fe13 0,1\% }\end{array}$ & $20-25$ & 0,2 \\
\hline $\begin{array}{l}\text { LLDPE } \\
+\mathrm{Al65Cu} 22 \mathrm{Fe} 131 \%\end{array}$ & $1,5-1,7$ & 0,2 \\
\hline $\begin{array}{l}\text { LLDPE } \\
+\mathrm{A} 165 \mathrm{Cu} 22 \mathrm{Fe} 135 \%\end{array}$ & $0,3-0,6$ & 0,3 \\
\hline $\begin{array}{l}\text { LLDPE }+ \\
\text { Al65Cu22Fe1310\% }\end{array}$ & $0,8-1,2$ & $0,18-0,22$ \\
\hline
\end{tabular}

As a result of the studies carried out, it was found that the friction coefficients of the obtained composites did not differ significantly and their values were in the range $f=0.18-0.30$. When studying the wear rate (Fig. 2), data were obtained that indicate that with an increase in the content of the quasicrystalline alloy in the polymer matrix, the wear rate decreases, therefore, this contributes to an increase in wear resistance.

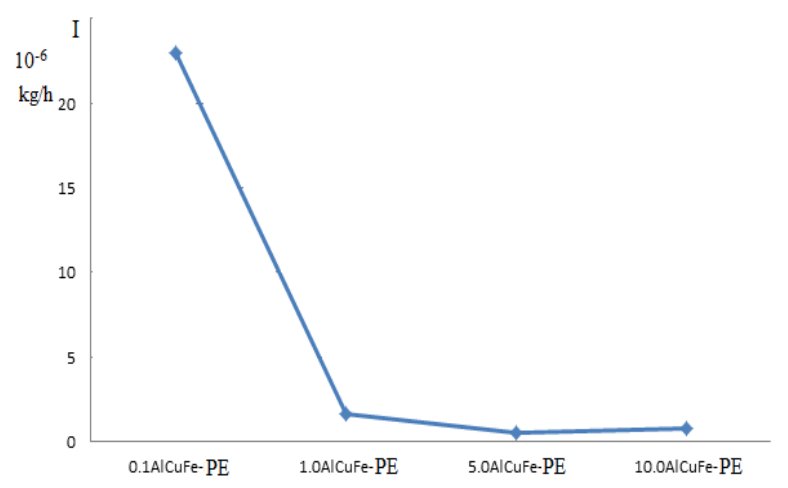

Fig. 2 The value of the wear rate of the composite depending on the content of the quasicrystalline alloy.

One of the most important characteristics of metals and alloys that affect the wear rate is hardness: with increasing hardness, the wear resistance of the material increases. In addition, the wear resistance of the material also depends on the coefficient of friction of the alloy. Since the friction coefficients of the studied samples differ insignificantly, the priority role in the formation of high wear resistance of the obtained composite should be given to the high value of the hardness of the quasicrystalline alloy.

\section{CONCLUSION}

The introduction of quasicrystal particles into a thermoplastic polymer leads to changes in the structure of polyethylene: the degree of crystallinity decreases from $42 \%$ (PE) to $27 \%(10 \mathrm{AlCuFe} / \mathrm{PE})$ with increasing concentration of the filler, the ratio of bands corresponding to amorphous and crystalline regions in the IR spectra changes, which indicates on the amorphization of the PE structure. The specimens have improved wear resistance (the wear rate decreased by $96 \%$ compared to the original PE), but the friction coefficient remained practically unchanged. From the data obtained it is seen that that the addition of quasicrystal nanoparticles in a small amount (up to $10 \mathrm{wt} . \%$ ) leads to an increase in hardness, but does not have a noticeable effect on the surface roughness. This means that the improved mechanical properties in this case are achieved. The results obtained indicate that quasicrystals can serve as effective fillers for promising polymeric materials in products for aerospace, instrument making, and other industries.

This study was funded by RFBR, project number 19-3190142. 


\section{REFERENCES}

[1] L. N. Rabinskiy, S. A. Sitnikov, "Development of technologies for obtaining composite material based on silicone binder for its further use in space electric rocket engines," Periodico Tche Quimica, 15(Special Issue 1), pp. 390-395, 2018.

[2] V. F. Formalev, S. A. Kolesnik, E. L. Kuznetsova, "Analytical study on heat transfer in anisotropic space with thermal conductivity tensor components depending on temperature," Periodico Tche Quimica, 15(Special Issue 1), pp. 426-432, 2018.

[3] V. F. Formalev, S. A. Kolesnik, "Temperature-dependent anisotropic bodies thermal conductivity tensor components identification method," International Journal of Heat and Mass Transfer, 123, pp. 994-998, 2018.

[4] I. P. Lifanov, A. N. Astapov, V. S. Terentieva, "Deposition of heat-resistant coatings based on the $\mathrm{ZrSi2}-$ MoSi2-ZrB2 system for protection of non-metallic composite materials in high-speed high-enthalpy gas flows," Journal of Physics: Conference Series, vol. 1713, no. 1, pp. 012025, 2018.

[5] O. A. Butusova, "Design and Properties of Magnetically Controlled Sorbents," Turkish Journal of Computer and Mathematics Education (TURCOMAT), vol. 12, no. 5, pp. 515-519, 2021.

[6] N. A. Kucheva, V. Kohlert, "Mathematical modeling methods for estimation the thermophysical properties of heat-protective composite materials," Turkish Journal of Computer and Mathematics Education (TURCOMAT), vol. 12, no. 10, pp. 1606-1612, 2021.

[7] I. P. Lifanov, A. A. Yurishcheva, A. N. Astapov, "Hightemperature protective coatings on carbon composites," Russian Engineering Research, vol. 39, no. 9, pp. $804-$ 808, 2019.

[8] A. N. Astapov, I. P. Lifanov, M. V. Prokofiev, "Hightemperature interaction in the $\mathrm{ZrSi} 2-\mathrm{ZrSiO} 4$ system and its mechanism," Russian Metallurgy (Metally), vol. 6, pp. $640-646,2019$.

[9] O. A. Butusova, "Application of Magnetically Controlled Sorbents for Detoxication," Turkish Journal of Computer and Mathematics Education (TURCOMAT), vol. 12, no. 5, pp. 520-524, 2021.

[10] V. F. Formalev, S. A. Kolesnik, E. L. Kuznetsova, "Analytical solution-based study of the nonstationary thermal state of anisotropic composite materials," Composites: Mechanics, Computations, Applications, 9(3), pp. 223-237, 2018.

[11]N. A. Kucheva, "Investigation of the mechanical properties of heat-protective highly porous composite materials using the effective medium model," Turkish Journal of Computer and Mathematics Education (TURCOMAT), vol. 12, no. 10, pp. 1613-1621, 2021.

[12] V. F. Formalev, S. A. Kolesnik, "On Thermal Solitons during Wave Heat Transfer in Restricted Areas," High Temperature, 57(4), pp. 498-502, 2019.

[13] V. F. Formalev, S. A. Kolesnik, E. L. Kuznetsova, L. N. Rabinskiy, "Origination and propagation of temperature solitons with wave heat transfer in the bounded area during additive technological processes," Periodico Tche Quimica, 16(33), pp. 505-515, 2019.

[14] V. F. Formalev, S. A. Kolesnik, E. L. Kuznetsova, "Mathematical modeling of a new method of thermal protection based on the injection of special coolants," Periodico Tche Quimica, 16(32), pp. 598-607, 2019.

[15] O. A. Pashkov, "Influence of Polymer Coatings on the Mechanical Properties of Steel Samples in Tensile and Bending Tests," Turkish Journal of Computer and Mathematics Education (TURCOMAT), vol. 12, no. 5, pp. 542-548, 2021.

[16] O. A. Pashkov, "Investigation of the Effect of Steel Plate Size and Elevated Temperature on Critical Load in Stability Tests," Turkish Journal of Computer and Mathematics Education (TURCOMAT), vol. 12, no. 10, pp. 1657-1663, 2021.

[17] O. A. Butusova, "Surface Modification of Titanium Dioxide Microparticles Under Ultrasonic Treatment," International Journal of Pharmaceutical Research, vol. 12, i. 4, pp. 2292-2296, 2020.

[18] O. A. Butusova, "Stabilization of Carbon Microparticles by High-Molecular Surfactants," International Journal of Pharmaceutical Research, vol. 12, Supplementary Issue 2, pp. 1147-1151, 2020.

[19] Yu. V. Ioni, A. Ethiraj, "New Tailor-Made Polymer Stabilizers for Aqueous Dispersions of Hydrophobic Carbon Nanoparticles," International Journal of Pharmaceutical Research, vol. 12, i. 4, pp. 3443-3446, 2020.

[20] Yu. V. Ioni, "Nanoparticles of noble metals on the surface of graphene flakes," Periodico Tche Quimica, vol. 17, no. 36, pp. 1199-1211, 2020.

[21] O. A. Butusova, "Vinyl Ether Copolymers as Stabilizers of Carbon Black Suspensions," International Journal of Pharmaceutical Research, vol. 12, Supplementary Issue 2, pp. 1152-1155, 2020.

[22] M. O. Kaptakov, "Catalytic Desulfuration of Oil Products under Ultrasonic Treatment," International Journal of Pharmaceutical Research, vol. 12, Supplementary Issue 2, pp. 1838-1843, 2020.

[23]B. A. Garibyan, "Enhancement of Mechanical Properties of Inorganic Glass under Ultrasonic Treatment," International Journal of Pharmaceutical Research, vol. 12, Supplementary Issue 2, pp. 1829-1832, 2020.

[24]M. O. Kaptakov, "Enhancement of Quality of Oil Products under Ultrasonic Treatment," International Journal of Pharmaceutical Research, vol. 12, Supplementary Issue 2, pp. 1851-1855, 2020.

[25]O. A. Butusova, "Adsorption Behaviour of Ethylhydroxyethyl Cellulose on the Surface of Microparticles of Titanium and Ferrous Oxides," International Journal of Pharmaceutical Research, vol. 12, Supplementary Issue 2, pp. 1156-1159, 2020.

[26]A. N. Tarasova, "Vibration-based Method for Mechanochemical Coating Metallic Surfaces," International Journal of Pharmaceutical Research, vol. 12, Supplementary Issue 2, pp. 1160-1168, 2020. 
[27]B. A. Garibyan, "Mechanical Properties of Electroconductive Ceramics," International Journal of Pharmaceutical Research, vol. 12, Supplementary Issue 2, pp. 1825-1828, 2020.

[28]M. O. Kaptakov, "Effect of Ultrasonic Treatment on Stability of $\mathrm{TiO}_{2}$ Aqueous Dispersions in Presence of Water-Soluble Polymers," International Journal of Pharmaceutical Research, vol. 12, Supplementary Issue 2, pp. 1821-1824, 2020.

[29] Yu. V. Ioni, "Synthesis of Metal Oxide Nanoparticles and Formation of Nanostructured Layers on Surfaces under Ultrasonic Vibrations," International Journal of Pharmaceutical Research, vol. 12, i. 4, pp. 3432-3435, 2020.

[30]A. N. Tarasova, "Effect of Reagent Concentrations on Equilibria in Water-Soluble Complexes," International Journal of Pharmaceutical Research, vol. 12, Supplementary Issue 2, pp. 1169-1172, 2020.

[31]A. N. Tarasova, "Effect of Vibration on Physical Properties of Polymeric Latexes," International Journal of Pharmaceutical Research, vol. 12, Supplementary Issue 2, pp. 1173-1180, 2020.

[32] Yu. V. Ioni, A. Ethiraj, "Study of Microparticles Surface Modification by Electrokinetic Potential Measuring," International Journal of Pharmaceutical Research, vol. 12, i. 4, pp. 3436-3439, 2020.

[33] Yu. V. Ioni, "Effect of Ultrasonic Treatment on Properties of Aqueous Dispersions of Inorganic and Organic Particles in Presence of Water-Soluble Polymers," International Journal of Pharmaceutical Research, vol. 12, i. 4, pp. 3440-3442, 2020.

[34] Y. Sun, O. V. Egorova, E. L. Kuznetsova, "Identification of the front angle of a plane acoustic oblique pressure wave on convex surfaces with the use of analytical solution," Journal of the Balkan Tribological Association, 27(2), pp. 189-197б 2021.

[35] V. F. Formalev, S. A. Kolesnik, "On Inverse Coefficient Heat-Conduction Problems on Reconstruction of Nonlinear Components of the Thermal-Conductivity Tensor of Anisotropic Bodies," Journal of Engineering Physics and Thermophysics, 90(6), pp. 1302-1309, 2017.

[36] G. A. Kalugina, A. V. Ryapukhin, "Impact of the 2020 Pandemic on Russian Aviation," Russian Engineering Research, vol. 41. no. 7, pp. 627-630, 2021.

[37]R. N. Zaripov, I. M. Murakaev, A. V. Ryapukhin, "Development of the Organization's Key Performance Indicators System in Order to Improve the Effectiveness of Its Human Capital and Risk Management," TEM Journal, vol. 10, no. 1, pp. 298-302, 2021.

[38] A. A. Kalugin, G. A. Kalugina, A. V. Ryapukhin, "Informational Support for the Sale of Passenger Aircraft," Russian Engineering Research, vol. 41, no. 2, pp. 183-187, 2021.

[39] R. N. Zaripov, I. M. Murakaev, S. V. Novikov, A. V. Ryapukhin, "Corporate Structure for Innovative Enterprises," Russian Engineering Research, vol. 40, no. 2, pp. 137-139, 2020.
[40]N. A. Bulychev, E. L. Kuznetsova, "Ultrasonic Application of Nanostructured Coatings on Metals," Russian Engineering Research, 39 (9), pp. 809-812, 2019.

[41] N. A. Bulychev, V. V. Bodryshev, L. N. Rabinskiy, "Analysis of geometric characteristics of two-phase polymer-solvent systems during the separation of solutions according to the intensity of the image of micrographs," Periodico Tche Quimica, 16(32), pp. 551559, 2019.

[42] N. A. Bulychev, A. V. Ivanov, "Effect of vibration on structure and properties of polymeric membranes," International Journal of Nanotechnology, vol. 16, nos. 6/7/8/9/10, pp. 334 - 343, 2019.

[43] N. A. Bulychev, A. V. Ivanov, "Nanostructure of OrganicInorganic Composite Materials Based on Polymer Hydrogels," International Journal of Nanotechnology, vol. 16, nos. 6/7/8/9/10, pp. 344 - 355, 2019.

[44] N. A. Bulychev, A. V. Ivanov, "Study of Nanostructure of Polymer Adsorption Layers on the Particles Surface of Titanium Dioxide," International Journal of Nanotechnology, vol. 16, nos. 6/7/8/9/10, pp. 356 - 365, 2019.

[45] N. A. Bulychev, L. N. Rabinskiy, O. V. Tushavina, "Effect of intense mechanical vibration of ultrasonic frequency on thermal unstable low-temperature plasma," Nanoscience and Technology: An International Journal, 11 (1), pp. 15-21, 2020.

[46] N. A. Bulychev, L. N. Rabinskiy, "Ceramic Nanostructures Obtained by Acoustoplasma Technique," Nanoscience and Technology: An International Journal, 10 (3), pp. 279-286, 2019.

[47] V. F. Formalev, S. A. Kolesnik, "Analytical investigation of heat transfer in an anisotropic band with heat fluxes assigned at the boundaries," Journal of Engineering Physics and Thermophysics, 89(4), pp. 975-984, 2016.

[48] V. F, Formalev, E. M. Kartashov, S. A. Kolesnik, "Simulation of Nonequilibrium Heat Transfer in an Anisotropic Semispace Under the Action of a Point Heat Source," Journal of Engineering Physics and Thermophysics, 92(6), pp. 1537-1547, 2019.

[49]I. S. Kurchatov, N. A. Bulychev, S. A. Kolesnik, "Obtaining Spectral Characteristics of Semiconductors of AIIBVI Type Alloyed with Iron Ions Using Direct Matrix Analysis," International Journal of Recent Technology and Engineering, vol. 8, i. 3, pp. 8328-8330, 2019.

[50] O. A. Pashkov, "Theoretical calculation of the thickness of interphase zones in the Al-Al2O3 composite," Turkish Journal of Computer and Mathematics Education (TURCOMAT), vol. 12, no. 10, pp. 1672-1677, 2021.

[51] O. A. Pashkov, "Experimental and Theoretical Study of Mechanical Properties of Matrix Composite Materials," Turkish Journal of Computer and Mathematics Education (TURCOMAT), vol. 12, no. 10, pp. 1678-1684, 2021.

[52] V. F. Formalev, S. A. Kolesnik, E. L. Kuznetsova, "Identification of new law for decomposition of bonding heat-shielding composite materials," Asia Life Sciences, (1), pp. 139-148, 2019. 
[53] N. A. Kucheva, V. Kohlert, "Analytical solution of the problem of thermoelasticity for a plate heated by a source with a constant heat supply on one surface," Turkish Journal of Computer and Mathematics Education (TURCOMAT), vol. 12, no. 10, pp. 1622-1633, 2021.

[54] V. F. Formalev, S. A. Kolesnik, B. A. Garibyan, "Mathematical modeling of heat transfer in anisotropic plate with internal sinks," AIP Conference Proceedings, 2181, 02000362019.

[55] V. F. Formalev, S. A. Kolesnik, B. A. Garibyan, "Heat transfer with absorption in anisotropic thermal protection of high-temperature products," Herald of the Bauman Moscow State Technical University, Series Natural Sciences, (5), pp. 35-49, 2019.

[56] S. A. Kolesnik, N. A. Bulychev, "Numerical analytic method for solving the inverse coefficient problem of heat conduction in anisotropic half-space," Journal of Physics: Conference Series, 1474(1), 012024, 2020.

[57] V. F. Formalev, N. A. Bulychev, S. A. Kolesnik, M. A. Kazaryan, "Thermal state of the package of cooled gasdynamic microlasers," Proceedings of SPIE - The International Society for Optical Engineering, 11322, article number 113221B, 2019.

[58] V. F. Formalev, S. A. Kolesnik, B. A. Garibyan, "Analytical solution of the problem of conjugate heat transfer between a gasdynamic boundary layer and anisotropic strip," Herald of the Bauman Moscow State Technical University, Series Natural Sciences, 5(92), pp. 44-59, 2020.

[59] Y. Sun, S. A. Kolesnik, E. L. Kuznetsova, "Mathematical modeling of coupled heat transfer on cooled gas turbine blades," INCAS Bulletin, 12(Special Issue), pp. 193-200, 2020.

[60]M. O. Kaptakov, "Effect of Thin Polymer Layers on Mechanical Properties of Metal Surfaces," Turkish Journal of Computer and Mathematics Education (TURCOMAT), vol. 12, no. 5, pp. 525-529, 2021.

[61] B. A. Garibyan, "Determination of the Elastic Modulus of the Coating Using a Spherical Indenter," Turkish Journal of Computer and Mathematics Education (TURCOMAT), vol. 12, no. 10, pp. 1594-1600, 2021.

[62] M. O. Kaptakov, "Modelling of Mechanical Properties of Metal Plates with Polymer Coatings," Turkish Journal of Computer and Mathematics Education (TURCOMAT), vol. 12, no. 5, pp. 530-534, 2021.

[63] B. A. Garibyan, "Theoretical Estimations of Influence of Polymer Coatings on the Elastic Modulus and Ultimate Strength of Steel Samples," Turkish Journal of Computer and Mathematics Education (TURCOMAT), vol. 12, no. 10, pp. 1651-1656, 2021.

[64] M. O. Kaptakov, "Investigation of Effective Mechanical Characteristics of Nanomodified Carbon-Epoxide Composite by Numerical and Analytical Methods," Turkish Journal of Computer and Mathematics Education (TURCOMAT), vol. 12, no. 5, pp. 535-541, 2021.

[65] M. O. Kaptakov, "Obtaining of Carbon Fibers Based Composite Materials and Study of Their Mechanical Properties," Turkish Journal of Computer and
Mathematics Education (TURCOMAT), vol. 12, no. 10, pp. 1601-1605, 2021.

[66] I. Kurchatov, N. Bulychev, S. Kolesnik, E. Muravev, "Application of the direct matrix analysis method for calculating the parameters of the luminescence spectra of the iron ion in zinc sulfide crystals," AIP Conference Proceedings, 2181, 020015, 2019.

[67]B. A. Antufev, E. L. Kuznetsova, L. N. Rabinskiy, O. V. Tushavina, "Investigation of a complex stress-strain state of a cylindrical shell with a dynamically collapsing internal elastic base under the influence of temperature fields of various physical nature," Asia Life Sciences, (2), pp. 689-696, 2019.

[68] B. A. Antufev, E. L. Kuznetsova, L. N. Rabinskiy, O. V. Tushavina, "Complex stressed deformed state of a cylindrical shell with a dynamically destructive internal elastic base under the action of temperature fields of various physical nature," Asia Life Sciences, (2), pp. 775782, 2019.

[69] L. N. Rabinskiy, O. V. Tushavina, "Problems of land reclamation and heat protection of biological objects against contamination by the aviation and rocket launch site," Journal of Environmental Management and Tourism, 10(5), pp. 967-973, 2019.

[70] A. N. Astapov, I. P. Lifanov, L. N. Rabinskiy, "Perspective Heat-Resistant Coating for Protection of Cf/SiC Composites in Air Plasma Hypersonic Flow," High Temperature, 57(5), pp. 744-752, 2019.

[71] V. N. Dobryanskiy, L. N. Rabinskiy, O. V. Tushavina, "Validation of methodology for modeling effects of loss of stability in thin-walled parts manufactured using SLM technology," Periodico Tche Quimica, 16(33), pp. 650656, 2019.

\section{Creative Commons Attribution License 4.0} (Attribution 4.0 International, CC BY 4.0)

This article is published under the terms of the Creative Commons Attribution License 4.0

https://creativecommons.org/licenses/by/4.0/deed.en_US 